\title{
Management of Rhabdomyolysis in a Patient Treated with Clozapine: A Case Report and Clinical Recommendations
}

\author{
Laurent Béchard ${ }^{1,2,3}$, Olivier Corbeil ${ }^{1,2,3}$, Marc-André Thivierge ${ }^{1}$, Ibrahim Assaad ${ }^{1}$, Camille Boulanger', \\ Marie-Pierre Mailhot ${ }^{2,4}$, Alexis Turgeon-Fournier ${ }^{5,6}$, Marc-André Roy ${ }^{2,3,4}$, Marie-France Demers ${ }^{1,2,3}$ \\ ${ }^{1}$ Faculty of Pharmacy, Laval University, ${ }^{2}$ Notre-Dame des Victoires Clinic, University Institute in Mental Health of Quebec, Integrated University \\ Health and Social Services Centres, Capitale-Nationale, ${ }^{3}$ CERVO Research Center, ${ }^{4}$ Department of Psychiatry and Neurosciences, Faculty of \\ Medicine, Laval University, ${ }^{5}$ Department of Anesthesiology and Critical Care Medicine, Division of Critical Care Medicine, Laval University, \\ ${ }^{6}$ Department of Anesthesiology \& Department of Medicine, Population Health and Optimal Health Practices Research Unit \\ (Trauma-Emergency-Critical Care Medicine), CHU de Québec-Université Laval Research Center, Quebec City, QC, Canada
}

Clozapine has a unique efficacy in treatment-resistant schizophrenia. Its use is, however, associated with potential adverse events. Among those, clozapine induced rhabdomyolysis can compromise clozapine treatment. Recommendations surrounding the management of this rare adverse event are limited. We present a case of clozapine-induced rhabdomyolysis. A 20-year-old Caucasian male diagnosed with resistant schizophrenia developed, after a 5-month total exposition and a significant response to treatment, a marked creatine kinase (CK) elevation and important myalgia in the weeks following an increment from 175 to $200 \mathrm{mg}$ of the daily dose of clozapine. This event also coincided with weight training as reported by the patient. The patient was hospitalized, and the clozapine was stopped following the diagnosis of rhabdomyolysis (CK 45,564 U/L). The cause of rhabdomyolysis was thoroughly investigated, and clozapine was held accountable for most. Clozapine cessation led to a severe psychotic relapse. Clozapine rechallenge while strictly monitoring CK was then performed allowing a significant clinical response. Clozapine was pursued despite two other episodes of mild CK elevations observed following weight training. Rhabdomyolysis comes as a rare adverse event of clozapine and its mechanism is poorly understood. Evidence on clozapine rechallenge following this adverse event is lacking and the innocuity of such practice is unknown. The unique aspect of our case report is that a shared decision with the medical team, patient and family led to a proactive clozapine rechallenge. More research is needed to provide robust guidelines and evidenced based approaches for clinicians in such a clinical dilemma.

KEY WORDS: Rhabdomyolysis; Creatine kinase; Clozapine; Rechallenge; Schizophrenia.

\section{INTRODUCTION}

Rhabdomyolysis designates an important muscle cell injury causing a release of cellular waste and creatine kinase (CK) into the blood stream. Rhabdomyolysis may constitute a medical emergency as it can lead to life-threatening complications including acute kidney injury. While rhabdomyolysis is often considered pathological when

Received: February 16, 2021 / Revised: April 8, 2021

Accepted: June 14, 2021

Address for correspondence: Laurent Béchard

Notre-Dame des Victoires Clinic, University Institute in Mental

Health of Quebec, 2525, Chemin de la Canardière, Entrée \#A-1-2,

Quebec City, QC G1J 2G3, Canada

E-mail: laurent.bechard.1@ulaval.ca

ORCID: https://orcid.org/0000-0001-6697-1799
CK levels exceed 1,000 U/L, there is no universal validated definition as individual factors such as gender, ethnicity, muscle mass, age and kidney functions may alter the CK levels and the urgency to intervene [1-3]. Treatment of uncomplicated rhabdomyolysis consists of fluid replacement therapy and forced diuresis [1]. Common causes include trauma, prolonged immobilization, intense exercise as well as certain drugs [1]. Particular attention must also be paid to differential diagnoses such as neuroleptic malignant syndrome (NMS), serotonin syndrome and illicit drug intoxication. Clozapine, a unique, more efficient antipsychotic used in treatment-resistant schizophrenia, has been associated with CK elevations and rhabdomyolysis, although the association with the latter remains nebulous [4-6]. In such cir-

(c) This is an Open-Access article distributed under the terms of the Creative Commons Attribution Non-Commercial License (http://creativecommons.org/licenses/by-nc/4.0) which permits unrestricted non-commercial use, distribution, and reproduction in any medium, provided the original work is properly cited. 
cumstances, clozapine may be withdrawn, compromising the patient's chances of recovery [4]. The clinical dilemma of clozapine rechallenge then arises, as described in this case report. Research Ethics Board approval was not required for this type of work according to the policy of the institution. The case was sufficiently altered to ensure confidentiality.

\section{CASE}

A 20-year-old Caucasian of male sex was diagnosed in his early adolescence with the Diagnostic and Statistical Manual of Mental Disorders 5th edition schizophrenia, cannabis use disorder and social anxiety disorder. His most troublesome psychotic symptom was a delusional belief that a fecal odour emanated from him. He had no other significant medical history. Oral risperidone was initially prescribed up to $2 \mathrm{mg}$ daily for 10 months with little improvement. As non-adherence was suspected, risperidone was changed for paliperidone palmitate $100 \mathrm{mg}$ monthly and maintained for a year. Due to partial response, treatment was replaced with quetiapine up to $1,000 \mathrm{mg}$ daily for the following year, with limited efficacy as reflected by a score of 5 (markedly ill) on the Clinical Global Impressions-Severity scale (CGI-S) [7]. During this period, the patient left school and lived a secluded existence with his mother while experiencing a 35 $\mathrm{kg}$ weight gain. Consequently, quetiapine was changed for clozapine, which was titrated up to $175 \mathrm{mg}$, yielding early on a significant improvement. Indeed, five months after clozapine initiation, the patient's CGI-S had decreased to 3 (mildly ill), his cannabis use disorder was in remission, he was planning on resuming school and he had recommenced social activities. Besides a further 10 $\mathrm{kg}$ weight gain, clozapine was well tolerated. He was concomitantly receiving sertraline $100 \mathrm{mg}$, which had been started three months after clozapine initiation, for his social anxiety disorder.

Three weeks after the clozapine dose was increased from 175 to $200 \mathrm{mg}$ to address residual psychotic symptoms, a blood test performed following complaints of muscular pain by the patient revealed CK levels of 7,499 $\mathrm{U} / \mathrm{L}$ (Fig. 1). The patient mentioned having done 30-60 minutes of low intensity weight training daily at home during the previous three days, after being sedentary for over a year. Following consult, he was immediately trans- ferred to a non-psychiatric medical facility. Clozapine was stopped on admission, benztropine was introduced to prevent a cholinergic rebound and aggressive fluid therapy was initiated as part of the treatment of rhabdomyolysis. Clozapine levels were within the normal range (439 nmol/L), recreational drug screening was negative and other laboratory results remained normal throughout the hospitalization. The physical exam and additional investigations yielded no additional abnormalities. Myocarditis and NMS were also ruled out. The patient denied taking any performance enhancement drug such as anabolic steroids or supplements. The patient's muscle mass was not important and his weight of $113 \mathrm{~kg}$ was mainly related to an overweight from sedentarity. Creatine kinase levels peaked at 45,564 U/L three days after clozapine cessation and were back to normal levels after 14 days. No further complication occurred. After exhaustive investigations and given that the magnitude of the increase in CK levels could not have been caused solely by the light intensity training of the patient, a clozapine-induced rhabdomyolysis was considered as the main diagnosis. Upon discharge, sertraline was discontinued, and the medical team agreed that clozapine rechallenge should be avoided.

The patient's mental status deteriorated in the following weeks while receiving aripiprazole $15 \mathrm{mg}$ daily and lorazepam on a regular basis. The severity of his psychopa-

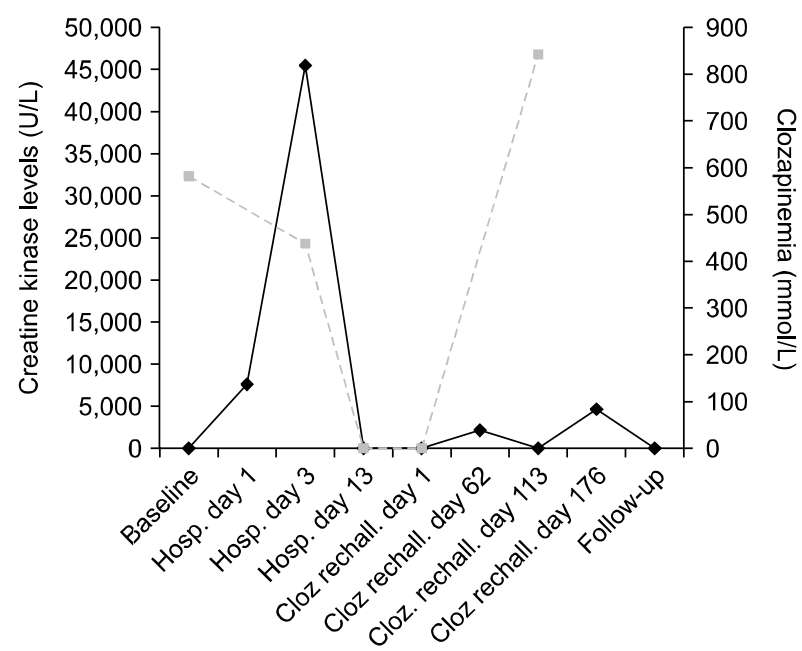

Fig. 1. Line graphic showing the evolution of creatine kinase levels and clozapinemia at different time points. Full line: creatine kinase levels. Dotted line: clozapinemia. Hosp. day, days after hospitalization; Cloz rechall. day, days after clozapine rechallenge. 
thology eventually reached a CGI-S score of 6 (severely ill) and he could no longer leave his house, convinced that he had a fetid odour. He was also experiencing continuous visual and auditory hallucinations. The patient and his family expressed their desire to restart clozapine four months after its interruption. After thoroughly explaining the potential risks, an outpatient clozapine re-initiation was allowed in agreement with an internist under strict conditions: liver enzymes and CK would be monitored weekly for a month, then biweekly for a month along with the usual monitoring protocol, and CK levels above 1,000 U/L would prompt immediate clozapine cessation. Also, the patient was instructed to avoid any moderate to high-intensity exercise. Clozapine was reinitiated at $6.25 \mathrm{mg}$ and slowly titrated up, initially with $12.5 \mathrm{mg}$ weekly increase and then $25 \mathrm{mg}$ weekly up to a maximum dose of $200 \mathrm{mg}$ at bedtime. Nine weeks later, CK levels increased to 2,218 U/L, a few days after the patient performed a light workout. Clozapine was nevertheless continued as this less significant CK increase was judged to be due to exercise and it normalized without any medical intervention within a week. Three months later, after two consecutive days of weight training, CK levels again increased to 4,734 U/L, but normalized within a week without any medical intervention. To this day, eight months after this rechallenge, the patient is still receiving clozapine $200 \mathrm{mg}$ daily and his CGI-S score is back to a 3 (mildly ill). He is planning on resuming school in the near future.

\section{DISCUSSION}

Clozapine has been shown to be associated with CK elevations of variable severity and cases of rhabdomyolysis have also been reported [4,5]. However, there is neither consensus on the definition of rhabdomyolysis nor on the CK threshold warranting clozapine withdrawal [2]. Furthermore, evidence on clozapine rechallenge following rhabdomyolysis is lacking and the safety of such a practice remains unknown. Hence, only nine cases putatively of rhabdomyolysis caused by clozapine have been published (Table 1). In seven of these cases, clozapine was withheld despite a debatable causality link given the presence of contributing factors and pharmacovigilance

Table 1. Literature review of clozapine induced rhabdomyolysis

\begin{tabular}{|c|c|c|c|c|c|c|c|}
\hline Author (yr) & $\begin{array}{c}\text { Max CLZ } \\
\text { dose }(\mathrm{mg} / \mathrm{d})\end{array}$ & Demographics & $\begin{array}{c}\text { Time of } \\
\text { onset }\end{array}$ & $\begin{array}{l}\text { CK peak } \\
(\mathrm{U} / \mathrm{L})\end{array}$ & Contributing factors & CLZ management & CLZ rechallenge \\
\hline $\begin{array}{l}\text { Koren et al. } \\
\text { (1998) [10] }\end{array}$ & NR & $\begin{array}{l}\text { 21-year-old } \\
\text { Ashkenazi } \\
\text { Jewish male }\end{array}$ & 15 weeks & $\sim 2,000$ & Red blood cell anomaly & Discontinuation & Unsuccessful \\
\hline $\begin{array}{l}\text { Wicki et al. } \\
\text { (1998) [11] }\end{array}$ & 300 & 42-year-old male & 2 months & 62,730 & Hyponatremia, seizure & Discontinuation & Successful \\
\hline $\begin{array}{l}\text { Tényi and Vörös } \\
\text { (2006) [12] }\end{array}$ & 400 & 46-year-old & 4 years & 52,090 & Hyponatremia, seizure & $\begin{array}{l}\text { Switched to } \\
\text { olanzapine }\end{array}$ & Unattempted \\
\hline $\begin{array}{l}\text { Tseng and } \\
\text { Hwang (2009) } \\
\text { [13] }\end{array}$ & 500 & $\begin{array}{l}\text { 29-year-old } \\
\text { Taiwanese male }\end{array}$ & 3 months & 6,776 & $\begin{array}{l}\text { ECT, recent clozapine } \\
\text { dose increase, valproic } \\
\text { acid and lithium. }\end{array}$ & $\begin{array}{l}\text { Dose decrease from } \\
500 \text { to } 400 \mathrm{mg}\end{array}$ & $\begin{array}{c}\text { Clozapine } \\
\text { treatment } \\
\text { pursued }\end{array}$ \\
\hline $\begin{array}{l}\text { Brouwers et al. } \\
\text { (2009) [14] }\end{array}$ & 900 & $\begin{array}{l}\text { 46-year-old } \\
\text { Caucasian male }\end{array}$ & NR & 195,000 & $\begin{array}{l}\text { Valproic acid, } \\
\text { ciprofloxacin, urosepsis, } \\
\text { drug-drug interaction }\end{array}$ & Discontinuation & Successful \\
\hline $\begin{array}{l}\text { Aguiar et al. } \\
\text { (2015) [15] }\end{array}$ & NR & 49-year-old male & Several years & 44,058 & $\begin{array}{l}\text { Hyponatremia, seizure, } \\
\text { rhabdomyolysis } \\
\text { recurrence }\end{array}$ & Discontinuation & Unattempted \\
\hline $\begin{array}{c}\text { Jansman et al. } \\
\text { (2015) [16] }\end{array}$ & 125 & 36-year-old male & NR & $\sim 12,000$ & $\begin{array}{l}\text { Clozapine intoxication, } \\
\text { immobilisation, delirium } \\
\text { tremens }\end{array}$ & NR & NR \\
\hline $\begin{array}{l}\text { Tseng et al. } \\
\text { (2020) [17] }\end{array}$ & 600 & 55-year-old male & $>10$ years & 18,638 & $\begin{array}{l}\text { Recent clozapine dose } \\
\text { increases, hypokalemia, } \\
\text { haloperidol, fever }\end{array}$ & Discontinuation & Unsuccessful \\
\hline $\begin{array}{l}\text { Béchard et al. } \\
\text { (2021) }\end{array}$ & 200 & $\begin{array}{l}\text { 20-year-old } \\
\text { Caucasian male }\end{array}$ & 6 months & 45,564 & Exercise, sertraline & Discontinuation & Successful \\
\hline
\end{tabular}

CK, creatine kinase; CLZ, clozapine; ECT, electroconvulsive therapy; NR, not reported; , approximately. 
tools were seldom used. Clozapine rechallenge was attempted in five of these cases and was considered successful in three of them. Of those nine identified cases, no death was reported.

In the present case, the peak CK level of $45,564 \mathrm{U} / \mathrm{L}$ associated with muscle pain leaves no doubt on the diagnosis of severe rhabdomyolysis [2]. On the other hand, the two further CK elevations of lesser severity are disputable for their clinical significance and whether they are secondary to the use of clozapine [8]. While a contribution of sertraline cannot be excluded, it was not considered as a significant factor as the patient had taken sertraline prior to starting clozapine without ever experiencing rhabdomyolysis. Furthermore, sertraline was not withdrawn until after the first rhabdomyolysis episode resolved, and thus its continuation did not preclude the resolution of the episode. A contribution of physical exercise could certainly be suspected as the rhabdomyolysis was not observed during the first sedentary five months that the patient was on clozapine and the two following CK elevations occurred each time after the patient exercised. Nevertheless, such a low intensity exercise, more so in the absence of dehydration, cannot explain a CK elevation as severe as the one that occurred in the initial episode. Based on this information, the Naranjo scale was used to assess clozapine imputability and the score obtained was 8 , indicating a "probable" link of causality; while the score for sertraline was 3 , reflecting only a "possible” link of causality [9].

Despite these considerations, a clozapine rechallenge was attempted at the request of the patient and his family, after an extensive discussion with the medical team, through a shared-decision process. Clozapine re-exposure was accompanied with a rigorous monitoring follow-up, as described earlier. Also, given the suspected exercise contribution, a personalized training plan was designed by a kinesiologist/nutritionist team and included appropriate hydration, diet, rest days, and low intensity exercises.

This case report highlights the complexity of managing clozapine after severe rhabdomyolysis. CK elevation should be rigorously investigated bearing in mind factors known to modulate CK levels before making any precipitate decisions. Asymptomatic CK elevation should not automatically deprive a person from clozapine, especially if a cause other than clozapine was identified. A risk-ben- efit assessment should be undertaken using a shared-decision making process with the patient and his family before attempting clozapine rechallenge in light of the unknown safety of this approach but also considering global health recovery perspectives. More research is warranted to provide evidence-based guidelines to help clinicians and their patients in confronting this clinical dilemma.

\section{Funding}

None.

\section{Conflicts of Interest}

LB has received a grant from Fond d'enseignement et de recherche of the Faculty of Pharmacy Université Laval. OC has received an honorarium from Janssen and Otsuka-Lundbeck Alliance and is currently receiving a grant from the Fonds de Recherche du Québec - Santé (FRQS). MAR and MFD have received grants from FRQS, Fonds de Recherche du Québec - FRQSC, SSHRC, CIHR; grants and honoraria from Otsuka-Lundbeck Alliance, Janssen and Mylan. AFT is the Canada Research Chair in Critical Care Neurology and Trauma. For the remaining authors, there are no potential conflicts of interest to disclose.

\section{Author Contributions}

Conceptualization : Laurent Béchard, Marc-André Thivierge, Ibrahim Assaad, Camille Boulanger, Marie-Pierre Mailhot, Marie-France Demers. Data acquisition : Laurent Béchard, Marc-André Thivierge, Camille Boulanger, Ibrahim Assaad. Formal analysis : Laurent Béchard, Olivier Corbeil, Marc-André Thivierge. Supervision : Marie-Pierre Mailhot, Marc-André Roy, Alexis Turgeon-Fournier, Marie-France Demers. Writing original draft : Laurent Béchard, Olivier Corbeil, Marc-André Thivierge. Writing review \& editing : Laurent Béchard, Olivier Corbeil, Marc-André Roy, Alexis Turgeon-Fournier, Marie-France Demers.

\section{ORCID}

Laurent Béchard https://orcid.org/0000-0001-6697-1799 Olivier Corbeil https://orcid.org/0000-0002-4192-853X Marc-André Thivierge

https://orcid.org/0000-0002-1321-6420

Ibrahim Assaad https://orcid.org/0000-0002-9871-7557

Camille Boulanger https://orcid.org/0000-0002-5469-8323 
Marie-Pierre Mailhot https://orcid.org/0000-0002-4520-3018 Alexis Turgeon-Fournier

https://orcid.org/0000-0001-5675-8791

Marc-André Roy https://orcid.org/0000-0002-0123-6651 Marie-France Demers

https://orcid.org/0000-0003-3017-0265

\section{REFERENCES}

1. Chavez LO, Leon M, Einav S, Varon J. Beyond muscle destruction: a systematic review of rhabdomyolysis for clinical practice. Crit Care 2016;20:135.

2. Stahl K, Rastelli E, Schoser B. A systematic review on the definition of rhabdomyolysis. J Neurol 2020;267:877-882.

3. Bokern $\mathrm{H}$, Jonker N, Cohen D. Creatine kinase elevation and discontinuation of clozapine: fear-driven clinical practice in a forensic case with treatment-resistant schizophrenia and persistent violent behaviour. BJPsych Open 2020;7:e4.

4. Laoutidis ZG, Kioulos KT. Antipsychotic-induced elevation of creatine kinase: a systematic review of the literature and recommendations for the clinical practice. Psychopharmacology (Berl) 2014;231:4255-4270.

5. Masi G, Milone A, Viglione V, Mancini A, Pisano S. Massive asymptomatic creatine kinase elevation in youth during antipsychotic drug treatment: case reports and critical review of the literature. J Child Adolesc Psychopharmacol 2014;24: 536-542.

6. Reznik I, Volchek L, Mester R, Kotler M, Sarova-Pinhas I, Spivak B, et al. Myotoxicity and neurotoxicity during clozapine treatment. Clin Neuropharmacol 2000;23:276-280.

7. Busner J, Targum SD. The clinical global impressions scale: applying a research tool in clinical practice. Psychiatry (Edgmont) 2007:4:28-37.

8. Huynh A, Leong K, Jones N, Crump N, Russell D, Anderson M, et al. Outcomes of exertional rhabdomyolysis following high-intensity resistance training. Intern Med J 2016;46: 602-608

9. Naranjo CA, Busto U, Sellers EM, Sandor P, Ruiz I, Roberts EA, et al. A method for estimating the probability of adverse drug reactions. Clin Pharmacol Ther 1981;30:239-245.

10. Koren W, Koren E, Nacasch N, Ehrenfeld M, Gur H. Rhabdomyolysis associated with clozapine treatment in a patient with decreased calcium-dependent potassium permeability of cell membranes. Clin Neuropharmacol 1998;21: 262-264.

11. Wicki J, Rutschmann OT, Burri H, Vecchietti G, Desmeules J. Rhabdomyolysis after correction of hyponatremia due to psychogenic polydipsia possibly complicated by clozapine. Ann Pharmacother 1998;32:892-895.

12. Tényi T, Vörös V. Successful switch to olanzapine after rhabdomyolysis caused by water intoxication and clozapine use. Pharmacopsychiatry 2006;39:157-158.

13. Tseng KC, Hwang TJ. Rhabdomyolysis following dose increase of clozapine and combination therapy with lithium. J Clin Psychopharmacol 2009;29:398-399.

14. Brouwers EE, Söhne M, Kuipers S, van Gorp EC, Schellens JH, Koks $\mathrm{CH}$, et al. Ciprofloxacin strongly inhibits clozapine metabolism: two case reports. Clin Drug Investig 2009;29:59-63.

15. Aguiar DT, Monteiro C, Coutinho P. Recurrent rhabdomyolysis secondary to hyponatremia in a patient with primary psychogenic polydipsia. Rev Bras Ter Intensiva 2015;27:77-81.

16. Jansman FG, Crommelin HA, van Hout FJ, Meulenbelt J. Rhabdomyolysis in clozapine overdose. Drug Saf Case Rep 2015;2:9.

17. Tseng CY, Chen MS, Lee KH, Ku CT, Chen YC, Lin PI. Rhabdomyolysis with clozapine and haloperidol coadministration: a case report. J Clin Psychopharmacol 2020;40: 502-504. 